\title{
Disease Milestones through Bibliometric Analysis of the Top 100 Cited Articles in Multiple Myeloma
}

Azka Latif ${ }^{1}$, Vikas Kapoor ${ }^{1}$, Qurat ul ain riaz Sipra ${ }^{2}$, Saad Ullah Malik ${ }^{1}$, Jawad Bilal ${ }^{3}$, Irbaz Bin Riaz $^{4}$, Faiz Anwer ${ }^{1}$

1. Hematology and Oncology, University of Arizona, Tucson, USA 2. Department of Internal Medicine, University of Arizona, Tucson, USA 3. Medicine, University of Arizona, Tucson, USA 4. Hematology and Oncology, Mayo Clinic and Foundation, Rochester, MN, USA

$\square$ Corresponding author: Jawad Bilal, jawad.bilal@hotmail.com

Disclosures can be found in Additional Information at the end of the article

\section{Abstract}

Multiple myeloma (MM) accounts for 1.6\% of all cancers and 5\%-10\% of all hematologic malignancies in the United States (US). Despite marked progress in disease management, it remains incurable with high rates of relapse. We conducted a bibliographic analysis on the Web of Science (WOS) from July 25, 2017 and July 29, 2017. Among the top 100 most-cited articles (1901-2012), the most cited article received 2404 citations and least cited article received 336 citations. Forty-four of 100 articles were published in journals with impact factors greater than 20. We observed that over the years, the focus of research has shifted from diagnosis, staging, and pathogenesis to better treatment outcomes. A subgroup analysis of the top 100 cited articles published in the last five years (2012-2017) demonstrated that several landmark studies, which will likely change the landscape of treating multiple myeloma, were not included in the top 100 list. Interestingly, most of these articles were focused on novel therapeutic agents. This bibliographic analysis provides a list of the 100 top-cited articles in multiple myeloma along with the captivating comprehension of the history and development in various aspects of disease processes. The landscape of this disease is rapidly evolving, and bibliometric studies such as the one presented provide a valuable tool that can highlight the important transitions in the field.

Received 12/03/2017

Review began 02/05/2018

Review ended 03/02/2018

Published 04/05/2018

๑) Copyright 2018

Latif et al. This is an open access article distributed under the terms of the Creative Commons Attribution License CC-BY 3.0., which permits unrestricted use, distribution, and reproduction in any medium, provided the original author and source are credited.
Categories: Internal Medicine, Oncology

Keywords: bibliometeric analysis, multiple myeloma, citation analysis

\section{Introduction And Background}

Multiple myeloma (MM) accounts for $1.6 \%$ of all cancers and $5 \%$ to $10 \%$ of all hematologic malignancies in the United States (US) [1]. Worldwide, approximately 154,000 cases are diagnosed, and 101,000 deaths are attributed to MM every year [2]. Due to the advent of novel therapeutic agents, median overall survival has increased from one to two years to seven to eight years with a meaningful improvement in the quality of life [1]. Although there has been marked progress in disease management, MM remains incurable with high rates of relapse. Ongoing clinical trials have significantly contributed to favourable disease outcomes; however, many of these interventions remain unknown to clinicians. This highlights the need for citation analysis to reflect these advances and substantial progress in this field.

Citation analysis is a type of bibliometric analysis in which evaluation and ranking of an article or journal is done on the basis citation count [3]. It identifies the milestones completed in 


\section{Cureus}

understanding core aspects of a disease and emphasizes on major developments made in the subject matter [4-5]. Clinicians often modify their disease management based on research published in high impact journals [6] thus if most important articles can be highlighted via citation analysis it will help clinicians in making better choices for their patients. So far, no such study has been performed to conclude the most influential articles in the field of MM. The aim of the current study is to identify the 100 top-cited publications in MM and highlight the most significant advances made in the field over the preceding several decades.

\section{Review}

\section{Materials and methods}

We conducted a bibliographic analysis on the Web of Science (WOS). The time covered in WOS is between 1900 and 2017. We included journals listed in the Science Citation Index Expanded, without specific restrictions on the journals. We retrieved articles for analysis by typing "Multiple Myeloma" into the WOS search box and conducted data search with the application of English language filter on July 25, 2017. We identified 27,718 articles that were published between 1901 and 2017, ranked the articles based on citation frequency from highest to lowest, and thereafter, shortlisted the top 100 cited articles. Statistical analysis of studies was not performed, and data were reported in the form of tables. To capture the most important and latest research, we conducted a second search on July 29, 2017 to limit articles to those published during the last five years.

\section{Results}

Among the top 100 included articles, the most cited article received 2404 citations while the least cited article received 336 citations. All articles were arranged according to citation frequency (Table 1). The top 100 cited articles were published between 1990 and 2007. In our analysis, we found that the highest number of articles were published in the year 2007 (Table 2). Forty-eight of the 100 articles were published in journals with impact factors (IF) greater than 20 (Table 3). The journal with the highest number of publications was Blood with 33\% of the publications (IF 13.16) followed by New England Journal of Medicine (NEJM) with $20 \%$ of the publications (IF 72.406). The country of origin with the highest number of publications on the topic of MM was the US ( $n=73$ ) followed by France ( $n=10)$, Italy, and Germany (Table 4). These 100 articles sourced from 50 major institutions, with top three most significant contributors being Dana Farber Cancer Institute, Mayo Clinic, and the University of Arkansas Medical Sciences (Table 5). Most articles focused on disease management followed by pathogenesis and disease staging respectively (Table 6).

\begin{tabular}{|c|c|c|c|c|}
\hline No. & Author & Title & Journal & $\begin{array}{l}\text { Number } \\
\text { of } \\
\text { Citations }\end{array}$ \\
\hline 1 & $\begin{array}{l}\text { Durie, BGM et } \\
\text { al. }\end{array}$ & $\begin{array}{l}\text { Clinical staging system for multiple-myeloma - } \\
\text { correlation of measured myeloma cell mass with } \\
\text { presenting clinical features, response to treatment, and } \\
\text { survival }\end{array}$ & $\begin{array}{l}\text { CANCER } \\
1975 ; 36(842) ; 1182674 ;\end{array}$ & 2404 \\
\hline 2 & Attal, M & $\begin{array}{l}\text { A prospective, randomized trial of autologous bone } \\
\text { marrow transplantation and chemotherapy in multiple } \\
\text { myeloma }\end{array}$ & $\begin{array}{l}\text { New England journal of } \\
\text { medicine } 1996 \mathrm{Jul} \\
11 ; 335(2): 91-7\end{array}$ & 1909 \\
\hline 3 & $\begin{array}{l}\text { Singhal, S et } \\
\text { al. }\end{array}$ & $\begin{array}{l}\text { Antitumor activity of thalidomide in refractory multiple } \\
\text { myeloma. }\end{array}$ & $\begin{array}{l}\text { New England journal of } \\
\text { medicine }\end{array}$ & 1665 \\
\hline
\end{tabular}




\section{Cureus}

Kawano, $M$ et Autocrine generation and requirement of bsf-2/il-6 for al.

human multiple myeloma

Richardson, Bortezomib or high-dose dexamethasone for relapsed PG et al. multiple myeloma

Durie, BGM et International uniform response criteria for multiple

al. myeloma

7

Child, JA et

al.

High-dose chemotherapy with hematopoietic stem-cell rescue for multiple myeloma

Greipp, PR et

al.

The proteasome inhibitor PS-341 inhibits growth,

9

Hideshima, T induces apoptosis, and overcomes drug resistance in

et al.

human multiple myeloma cells

10

Kumar, Shaji

et al.

Improved survival in multiple myeloma and the impact of

novel therapies

Criteria for the classification of monoclonal

11 Kyle, RA et al.

gammopathies, multiple myeloma and related disorders:

a report of the International Myeloma Working Group

12 San $\mathrm{M}$ et al.

Bortezomib plus melphalan and prednisone for initial treatment of multiple myeloma

13 Kyle RA et al. Drug therapy: Multiple myeloma

The role of the Wnt-signaling antagonist DKK1 in the development of osteolytic lesions in multiple myeloma

Dimopoulos, Lenalidomide plus dexamethasone for relapsed or $\mathrm{M}$ et al.

refractory multiple myeloma

Review of 1027 patients with newly diagnosed multiple myeloma

17 Kyle, RA et al. Multiple-myeloma - review of 869 cases

18

Palumbo, A et al.

Medical progress multiple myeloma

Weber, DM et Lenalidomide plus dexamethasone for relapsed multiple al.

myeloma in North America

20

Bernson, JR Efficacy of pamidronate in reducing skeletal events in et al. patients with advanced multiple myeloma
International staging system for multiple myeloma

1999;341(91);10564685

Nature

1988;332(83);3258060

1547

New England journal of

medicine

2005;352(2487);15958804

Leukemia

2006;20(1467);16855634

New England journal of

medicine

2003;348(1875);12736280

Journal of clinical oncology

2005;23(3412);15809451

1064

Cancer research

2001;61(3071);11306489

Blood

2008;111(2516);17975015

British journal of

Hematology

2003;121(749);12780789

NEJM

2008;359(906);18753647

NEJM

2004;351(1860);15509819

NEJM

2003;349(2483);14695408

NEJM

2007;357(2123);18032762

Mayo clinic proceedings

2003;78(21);12528874

mayo clinic proceedings

1975;50(29);1110582

NEJM

2011;364(1046);21410373

NEJM

2007;357(2133);18032763

NEJM

1996;334(488);8559201 


\section{Cureus}

21 Chapman, MA Initial genome sequencing and analysis of multiple et al. myeloma

Hideshima, T

22 et al.

NF-kappa B as a therapeutic target in multiple myeloma

Single versus double autologous stem-cell

transplantation for multiple myeloma

Hideshima, $\mathrm{T}$ Thalidomide and its analogs overcome drug resistance et al.

25

Dalton, WS et al.

Davies, FE et al.

of human multiple myeloma cells to conventional therapy

Drug-resistance in multiple-myeloma and non-Hodgkin's lymphoma - detection of p-glycoprotein and potential circumvention by addition of verapamil to chemotherapy

Thalidomide and immunomodulatory derivatives augment natural killer cell cytotoxicity in multiple myeloma

27

Barlogie, B et Effective treatment of advanced multiple-myeloma al. refractory to alkylating-agents

Annunziata,
28

Keats, JJ et

al.

29

Richardson, $P G$ et al.

30

Hallek, M et al.

31 $\mathrm{CM}$ et al.

32

Rajkumar, SV et al. Palumbo, A et al.

Promiscuous mutations activate the noncanonical NFkappa B pathway in multiple myeloma

Immunomodulatory drug CC-5013 overcomes drug resistance and is well tolerated in patients with relapsed multiple myeloma

Multiple myeloma: Increasing evidence for a multistep transformation process

Frequent engagement of the classical and alternative NF-kappa B pathways by diverse genetic abnormalities in multiple myeloma

Phase III clinical trial of thalidomide plus dexamethasone compared with dexamethasone alone in newly diagnosed multiple myeloma: A clinical trial coordinated by the eastern cooperative oncology group

Oral melphalan and prednisone chemotherapy plus thalidomide compared with melphalan and prednisone alone in elderly patients with multiple myeloma: randomised controlled-trial

Zoledronic acid versus pamidronate in the treatment of

34 Rosen, LS et al. seletal metastases in patients with breast cancer or double-blind, comparative trial

Melphalan and prednisone plus thalidomide versus

35 Facon, $\mathrm{T}$ et melphalan and prednisone alone or reduced-intensity autologous stem cell transplantation in elderly patients
Nature

$2011 ; 471(467) 21430775$

journal of biological

chemistry

662

2002;277(16639);11872748

NEJM

2003;349(2495);14695409

Blood

2000;96(243);11049970

Journal of clinical oncology

1989;7(415);2564428

Blood

2001;98(210);11418482

NEJM

1984;310(1353);6546971

Cancer Cell

2007;12(131);17692805

Blood

2002;100(3063);12384400

Blood 1998;91(3);9414264

Cancer Cell

2007;12(115);17692804

Journal of clinical oncology

2006;24(431);16365178

Lancet

2006;367(825);16530576

Cancer Journal

2001;7(377);11693896

Lancet

2007;370(1209);17920916 


\section{Cureus}

with multiple myeloma (IFM 99-06): a randomised trial et al.

multiple myeloma cells

The proteasome inhibitor PS-341 potentiates sensitivity

37

Mitsiades, N

et al.

38

DEPTOR Is an mTOR Inhibitor Frequently

et al.

Overexpressed in Multiple Myeloma Cells and Required

for Their Survival

39 Zhan, $\mathrm{F}$ et al. The molecular classification of multiple myeloma

Long-term efficacy and safety of zoledronic acid

compared with pamidronate disodium in the treatment of

40

Rosen, LS et al.

skeletal complications in patients with advanced multiple myeloma or breast carcinoma - A randomized, doubleblind, multicentre, comparative trial

41

Alexanian, R Treatment for multiple myeloma - combination

et al.
36 Mitsiades, $\mathrm{N}$ Molecular sequelae of proteasome inhibition in human

Proceedings of the national academy of sciences of

USA

2002;99(14374);12391322

Blood

2003;101(2377);12424198

Cell

2009;137(873);19446321

Blood

2006;108(2020);16728703

Cancer

2003;98(1735);14534891

Journal of American

Medical Association

1969;208(1689);5818682

Frequent translocation $\mathrm{t}(4 ; 14)(\mathrm{p} 16.3 ; \mathrm{q} 32.3)$ in multiple

42 Chesi, $\mathrm{M}$ et al

myeloma is associated with increased expression and activating mutations of fibroblast growth factor receptor 3

Nature Genetics

1997;16(260);9207791

Annals of Internal Medicine 1980;93(399);6159812

NEJM

2006;354(1021);16525139

Nature Reviews Cancer 2002;2(175);11990854

Blood

2006;107(4907);16507771

Blood

2004;103(2332);14630803

Lancet Oncology

2010;11(29);19853510

therapy for newly diagnosed multiple myeloma: an openlabel randomised controlled trial

Vacca, A et Bone-marrow angiogenesis and progression in multipleal. myeloma
British Journal of

Hematology

$1994 ; 87(503) ; 7527645$ 


\section{Cureus}

A novel orally active proteasome inhibitor induces al.

53

\section{Bharti, AC et}

al.

54

Mitsiades, $\mathrm{N}$ et al. distinct from Bortezomib potential, and matrix metalloproteinase-2 secretion parallel progression of human multiple myeloma

Curcumin (diferuloylmethane) down-regulates the apoptosis

Apoptotic signalling induced by immunomodulatory apoptosis in multiple myeloma cells with mechanisms

Bone marrow neovascularization, plasma cell angiogenic constitutive activation of nuclear factor-kappa B and I kappa B alpha kinase in human multiple myeloma cells, leading to suppression of proliferation and induction of thalidomide analogs in human multiple myeloma cells: therapeutic implications

Genetic abnormalities and survival in multiple myeloma:

55 Avet, LH et al. the experience of the Intergroupe Francophone du Myelome

Inhibition of the insulin-like growth factor receptor-1

56 Mitsiades, CS tyrosine kinase activity as a therapeutic strategy for et al. multiple myeloma, other hematologic malignancies, and solid tumors

57 Klein, B et al. Interleukin-6 in human multiple-myeloma

Hideshima, $\mathrm{T}$ Understanding multiple myeloma pathogenesis in the et al. bone marrow to identify new therapeutic targets

59

Barlogie, B et Total therapy with tandem transplants for newly al. diagnosed multiple myeloma

60

Broder, S et al.

Impaired synthesis of polyclonal (non-paraprotein) immunoglobulins by circulating lymphocytes from patients with multiple-myeloma - role of suppressor cells

61

McCarthy, PL Lenalidomide after Stem-Cell Transplantation for et al. Multiple Myeloma

Global gene expression profiling of multiple myeloma,

62 Zhan, $\mathrm{F}$ et al. monoclonal gammopathy of undetermined significance, and normal bone marrow plasma cells

Ludwig, $\mathrm{H}$ et Erythropoietin treatment of anemia associated with al. multiple-myeloma

Stimulation of gamma delta T cells by

64

Kunzmann, V aminobisphosphonates and induction of antiplasma cell
Leukemia

2009;23(3);18971951

Cancer Cell

2005;8(407);16286248

Blood

1999;93(3064);10216103

Blood

2003;101(1053);12393461

Blood

2002;99(4525);12036884

Blood

2007;109(3489);17209057

Cancer Cell

2004;5(221);15050914

Blood

1995;85(863);7849308

Nature Reviews Cancer 2007;7(585);17646864

Blood 1999;9355);9864146

NEJM

1975;293(887);1080834

NEJM

2012;366(1770);22571201

Blood

2002;99(1745);11861292

NEJM

1990;322(1693);2342535

Blood

2000;96(384);10887096 


\section{Cureus}

65

Henry, DH et Zoledronic Acid in the Treatment of Bone Metastases in

al.

al.

Hideshima, T Advances in biology of multiple myeloma: clinical et al.

applications

Randomized phase III study of PEGylated liposomal

69

Orlowski, RZ

et al.

70

Shaughnessy

JD et al.

Berenson, JR et al.

72

Richardson,

$P G$ et al.

73 Attal, $\mathrm{M}$ et al.

Mitsiades, CS

et al.

Chauhan, D

et al.

77

Dankbar, B et al.

Patients with Advanced Cancer (Excluding Breast and

Prostate Cancer) or Multiple Myeloma

in patients with multiple myeloma

alone in relapsed or refractory multiple myeloma:

Combination therapy improves time to progression

A validated gene expression model of high-risk multiple myeloma is defined by deregulated expression of genes mapping to chromosome 1

myeloma patients reduces skeletal events

Transplantation for Multiple Myeloma inhibition in multiple myeloma: Biological and clinical implications

activation of NF-kappa B

Bortezomib with thalidomide plus dexamethasone compared with thalidomide plus dexamethasone as induction therapy before, and consolidation therapy after, double autologous stem-cell transplantation in newly diagnosed multiple myeloma: a randomised phase 3 study

Vascular endothelial growth factor and interleukin-6 in paracrine tumor-stromal cell interactions in multiple activity in multiple myeloma

Randomized, Double-Blind Study of Denosumab Versus

Maintenance, therapy with thalidomide improves survival Blood

2006;108(3289);16873668

Blood

1997;89(789);9028309

Blood

2004;104(607);15090448

Journal of Clinical Oncology

2007;25(3892);17679727

Blood

2007;109(2276);17105813

Journal of Clinical Oncology 1998;16(593);9469347

Blood

2010;116(679);20385792

NEJM

2012;366(1782);22571202

proceeding of the national academy of sciences of the united states of America

2004;101(540);14695887

Blood

1996;87(1104);8562936 myeloma
Blood

2000;95(2630);10753844 


\section{Cureus}

78

Retting, MB et al.

Weber, DM et al.

Moreau, $\mathrm{P}$ et

al.

81

Barlogie, B et

al.

82

Kyle RA et al. Multiple myeloma

Peripheral-blood stem-cell transplants for multiple-

83 Tricot, $\mathrm{G}$ et al.

myeloma - identification of favourable variables for rapid engraftment in 225 patients

84

Bataille, $\mathrm{R}$ et

al.

Multiple myeloma

Fonseca, $\mathrm{R}$ et al.

International Myeloma Working Group molecular

classification of multiple myeloma: spotlight review

Small-molecule inhibition of proteasome and aggresome

86

Hideshima, T

et al.

function induces synergistic antitumor activity in multiple myeloma

Sonneveld, P Modulation of multidrug-resistant multiple-myeloma by et al.

cyclosporine

Raab, MS et

al.

Multiple myeloma

Activation of NF-kappa B and upregulation of

Mitsiades, CS intracellular anti-apoptotic proteins via the IGF-1/Akt signalling in human multiple myeloma cells: therapeutic implications

Interleukin-6-dependent survival of multiple myeloma

Loeffler, D et

al.

cells involves the Stat3-mediated induction of microRNA-

21 through a highly conserved enhancer

91

Bergsagel, PL Cyclin D dysregulation: an early and unifying pathogenic et al.

event in multiple myeloma

Plerixafor and G-CSF versus placebo and G-CSF to mobilize hematopoietic stem cells for autologous stem cell transplantation in patients with multiple myeloma

Maintenance treatment with recombinant interferon alfa-

93

Mandelli, $\mathrm{F}$ et

$2 \mathrm{~b}$ in patients with multiple-myeloma responding to
Science

$1997 ; 276(1851) ; 9188529$

Journal of Clinical Oncology

2003;21(16);12506164

Lancet Oncology

2011;12(431);21507715

Blood

2001;98(492);11435324

Blood

2008;111(2962);18332230

Blood

$1995 ; 85(588) ; 7529066$

NEJM

$1997 ; 336(1657) ; 9171069$

Leukemia

2009;23(2210);19798094

proceedings of the national academy of sciences of the united states of America 2005;102(8567);15937109

Lancet

1992;340(255);1353189

Lancet

2009;374(324);19541364

Oncogene

2002;21(5673);12173037

Blood

2007;110(1330);17496199

Blood

2005;106(296);15755896

Blood

200;113(5720);19363221

NEJM 


\section{Cureus}

al.

94

Landgren, $\mathrm{O}$

et al.

95

Pasquali, S et al.

96

Fermand, JP et al.

98

Gupta, D et al.

99

Richardson, $P G$ et al.

100

Dispenzieri, A et al. conventional induction chemotherapy

Monoclonal gammopathy of undetermined significance

(MGUS) consistently precedes multiple myeloma: a prospective study

Combination chemotherapy versus melphalan plus prednisone as treatment for multiple myeloma: An overview of 6,633 patients from 27 randomized trials

High-dose therapy and autologous peripheral blood stem cell transplantation in multiple myeloma: Up-front or rescue treatment? Results of a multicentre sequential randomized clinical trial

A randomized phase 2 study of lenalidomide therapy for patients with relapsed or relapsed and refractory multiple myeloma

Adherence of multiple myeloma cells to bone marrow stromal cells upregulates vascular endothelial growth factor secretion: therapeutic applications

Frequency, characteristics, and reversibility of peripheral neuropathy during treatment of advanced multiple myeloma with bortezomib

International Myeloma Working Group guidelines for serum-free light chain analysis in multiple myeloma and related disorders
$190 ; 322(1430) ; 2184356$

Blood

2009;113(5412);19179464

Journal of Clinical Oncology

1998;16(3832);9850028

Blood

1998;92(3131);9787148

Blood

2006;108(3458);16840727

Leukemia

2001;15(1950);11753617

Journal of Clinical Oncology

2006;24(3113);16754936

Leukemia

2009;23(215);19020545

TABLE 1: Top 100 cited articles on the topic of multiple myeloma

\section{Publication Year}

2007

2006

2003

2009

2002

2005

2004

2001

2011

\section{Number of Records}

10

9

9

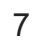

7

5

5

5

4 


\section{Cureus}

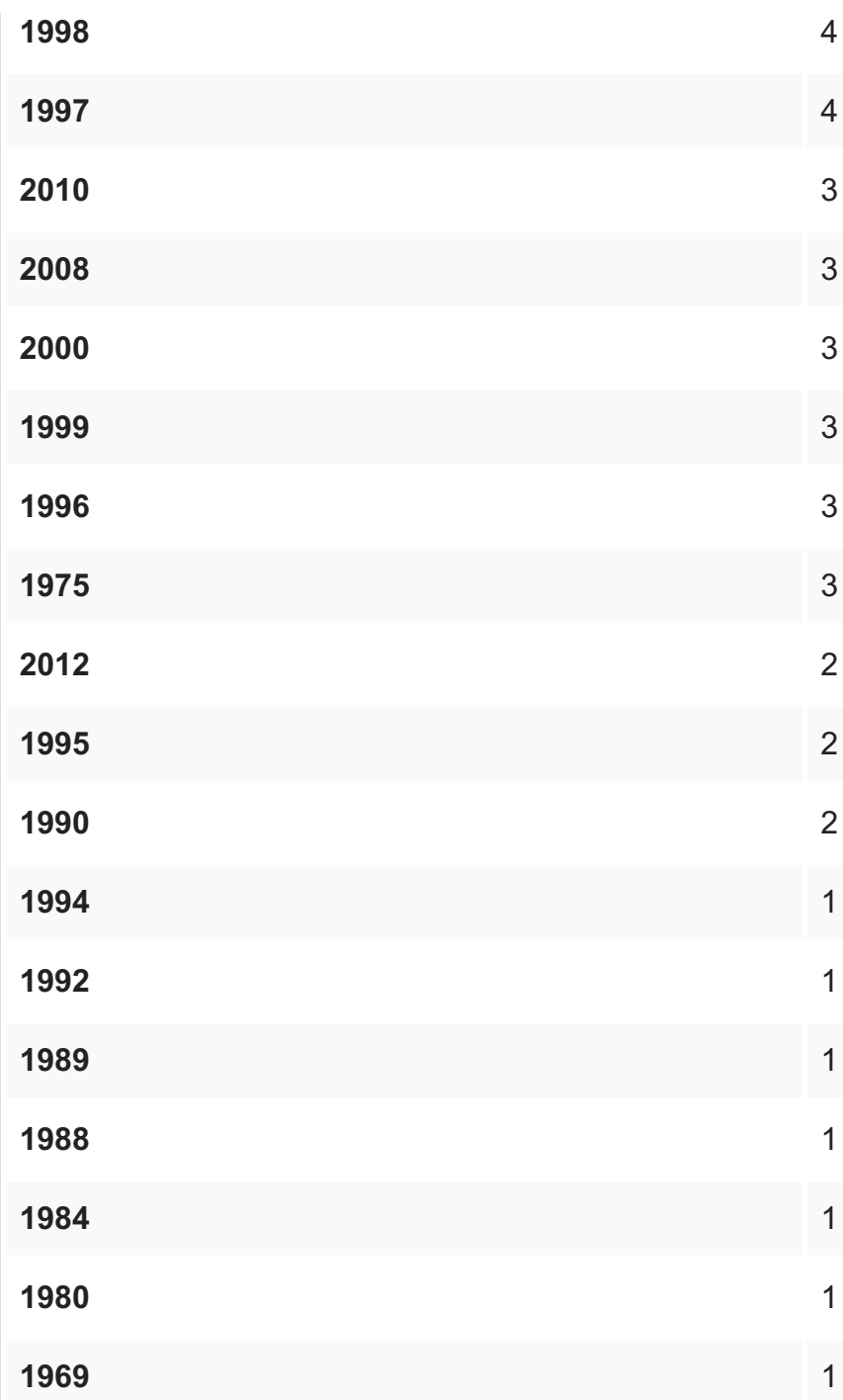

TABLE 2: Distribution of articles by year of publication 


\section{Cureus}

\begin{tabular}{|c|c|c|}
\hline Source Journals & $\begin{array}{l}\text { Impact } \\
\text { Factor }\end{array}$ & $\begin{array}{l}\text { Number of } \\
\text { Records }\end{array}$ \\
\hline Blood & 13.16 & 33 \\
\hline New England journal of medicine & 72.406 & 20 \\
\hline Journal of Clinical Oncology & 24.008 & 9 \\
\hline Leukemia & 11.702 & 5 \\
\hline The LANCET & 47.83 & 5 \\
\hline Cancer cell & 27.4 & 4 \\
\hline $\begin{array}{l}\text { Proceedings of The National Academy of Sciences of The United States of } \\
\text { America }\end{array}$ & 9.661 & 3 \\
\hline Nature reviews cancer & 37.147 & 2 \\
\hline Nature & 40.137 & 2 \\
\hline Mayo Clinic Proceedings & 6.686 & 2 \\
\hline LANCET Oncology & 33.9 & 2 \\
\hline Cancer & 5.99 & 2 \\
\hline British Journal of Haematology & 5.67 & 2 \\
\hline Cancer Research & 9.122 & 1 \\
\hline Journal of Biological Chemistry & 4.125 & 1 \\
\hline Cancer Journal & 4.218 & 1 \\
\hline Cell & 30.41 & 1 \\
\hline Journal of American Medical Association & 44.405 & 1 \\
\hline Nature Genetics & 27.959 & 1 \\
\hline Annals of Internal Medicine & 17.202 & 1 \\
\hline Science & 37.205 & 1 \\
\hline Oncogene & 7.519 & 1 \\
\hline
\end{tabular}

TABLE 3: Journals in which Top 100 cited articles were published 


\section{Cureus}

\begin{tabular}{l|l} 
Countries & Number of Records \\
\hline USA & 73 \\
\hline France & 10 \\
\hline Italy & 7 \\
Germany & 4 \\
England & 1 \\
Spain & 1 \\
Netherlands & 1 \\
Austria & 1 \\
Japan & 1 \\
Greece & 1
\end{tabular}

\section{TABLE 4: Country of origin for top 100 cited articles}

Institutions

Dana Farber Cancer Institute

Mayo Clinic

University of Arkansas Medical Sciences

UTMD Anderson Cancer Center

University of California Los Angeles

Chu de Toulouse

Chu de Nantes

NIH national cancer institute $(\mathrm{NCl})$

University of Turin

University of Bari Bari

University of Arizona

John Hopkins University

Eli \& Etdythe I. Broad Institute, Seven Cambridge Centers

University of Munich

Cancer Institute Medical Group

\section{Number of Records}

22

13

9

5

4

4

3

3

2

2

2

1

1

1

1 


\section{Cureus}

Adult division of The South West Cancer Chemotherapy Study Group 1

University of Miami Miller School of Medicine 1

University of South Carolina 1

Hiroshima University 1

Whitehead Institute Biomedical Research, Nine Cambridge Center 1

Bethesda Naval Hospital, Center Cancer Research 1

University of Leeds 1

$\begin{array}{ll}\text { International Myeloma Working Group } & 1\end{array}$

University of Athens School of Medicine 1

$\begin{array}{ll}\text { National Institute of Health } & 1\end{array}$

$\begin{array}{ll}\text { Chu Lille } & 1\end{array}$

$\begin{array}{ll}\text { University of Salamanca } & 1\end{array}$

$\begin{array}{ll}\text { University of Bologna } & 1\end{array}$

Sapienza University Rome 1

$\begin{array}{ll}\text { Erasmus University Rotterdam } & 1\end{array}$

Cedars Sinai Outpatient Cancer Center 1

$\begin{array}{ll}\text { University of Wurzburg } & 1\end{array}$

$\begin{array}{ll}\text { University of Muenster } & 1\end{array}$

Washington University 1

St Louis Hospital

University of North Carolina 1

$\begin{array}{ll}\text { University of Vienna } & 1\end{array}$

$\begin{array}{ll}\text { Institute of Molecular Genetics } & 1\end{array}$

$\begin{array}{ll}\text { Roswell Park Center Institute } & 1\end{array}$

$\begin{array}{ll}\text { University of Leipzig } & 1\end{array}$

Joan Karnell Cancer Center 1

Arcispedale Santa Maria Nuova

TABLE 5: Institutions contributing in the number of publications 


\section{Cureus}

\section{Category}

Management

Pathogenesis

Staging

Review Articles

\section{Number of Studies}

51

33

3

4

TABLE 6: Classification of articles by categories.

Regarding authors with the highest number of publications, Hideshima T and Mitsiades CS ranked first with six publications each, followed by Barlogie B, Kyle RA, and Richardson PG with five publications each, and Attal M with four publications (Table 7). Anderson KC was the top author with 26 publications as co-author. Most of the articles were categorized under the title of Hematology (40\%) followed by General Internal Medicine (29\%), and Oncology (27\%), respectively.

\begin{tabular}{|c|c|}
\hline Author Name & Number of Records \\
\hline Hideshima T & 6 \\
\hline Mitsiades CS & 6 \\
\hline Richardson PG & 5 \\
\hline Kyle RA & 5 \\
\hline Barlogie B & 5 \\
\hline Attal M & 4 \\
\hline Durie BGM & 2 \\
\hline Chauhan D & 2 \\
\hline Rajkumar SV & 2 \\
\hline Palumbo A & 2 \\
\hline Rosen LS & 2 \\
\hline Bernson JR & 2 \\
\hline Vacca A & 2 \\
\hline Weber DM & 2 \\
\hline Singhal S & 1 \\
\hline
\end{tabular}

TABLE 7: Most common first 15 authors 
A subgroup analysis was performed to capture the development and progress of MM therapy during the last five years. It demonstrated that the most cited article received 441 citations while the least cited article received only 70 citations. Forty-four of the 100 articles were published in 2012, 26 in 2013, and 20 in 2014. The top three journals targeted by authors were Blood (35\%), Journal of Clinical Oncology (11\%), and NEJM (11\%). The author with the most publications as the first author was Palumbo A with five publications, whereas the second position was shared by San-Miguel J, Kumar S, and Richardson PG with four publications each. The country with the highest output in last five years was the US (79\%). The top three research areas focused by authors were Hematology (50\%), Oncology (38\%), and General Internal Medicine (14\%).

\section{Discussion}

Bibliometric analysis has been used in the past to identify frontiers in specific fields and to evaluate the contribution of authors, institutions, and nations. The total number of citations received by an article represents its overall contribution to the clinical world.

Our study demonstrates that over the years, the focus of research has shifted from diagnosis, staging, and pathogenesis to better treatment outcomes in patients with MM (51 publications). The timeline for the evolution of MM therapy has progressed starting with melphalanprednisone in 1960's which was the standard of care for about 30 years. During the next 30 years, therapy further evolved when drugs such as vincristine, doxorubicin, and dexamethasone (VAD), alkylating agents such as Carmustine (VBAD), cyclophosphamide and melphalan (VCMP) were introduced. However, these therapeutic agents did not significantly improve the outcomes. High-dose melphalan followed by autologous stem cell transplant (ASCT) was a step towards favorable clinical outcomes. The armamentarium against MM was revolutionized by the development of ground-breaking agents such as immunomodulators (thalidomide and lenalidomide) and the proteasome inhibitor (bortezomib).

After better treatment outcomes, the most frequently encompassed category was disease pathogenesis (29 publications). Over the years, a thorough understanding of aetiological factors and relation of genetic aberrations to pathogenesis has laid the foundation for significant improvement in disease management and prognostication. Two of the top ten most cited articles were aimed at the staging of disease. The first being the Clinical Staging System proposed by Durie BGM et al., although the most cited article in our list is no longer the primary staging system. Modern-day physicians rely on the International Staging System (eighth most cited article) and cytogenetics to classify MM.

The findings of this analysis demonstrated that 32 of 100 articles were published in general medical journals, for which there may be several reasons. Firstly, general medicine journals capture a wide range of population compared to speciality journals. Secondly, patients with MM are usually co-managed by internists and oncologists which would make the general medicine audience more interested in advancements in MM. Lastly, the novel therapeutic options have different mechanisms of actions and extensive side effect profiles. It is very important for the general internist to be aware of these side effects to effectively manage these patients in both inpatient and outpatient settings.

The authors of these studies targeted high impact factor journals which is evidenced by the fact that most of the articles were published in journals with impact factors greater than 20 . This suggests that MM researchers tend to publish in prestigious and well-respected journals that capture a wide range of the population. We noted diversity amongst the authors, as only a total of 12 articles were contributed by the top two publishers as first authors. These findings suggest a diverse group of researchers involved in the MM field. 
Among the top 100 cited articles, only seven studies were focused on bortezomib-containing regimens, whereas none of them included carfilzomib or ixazomib based novel therapeutic regimens. This shows that articles with a high frequency of citations consisted mostly of earlypublished articles. Therefore, one limitation of such articles is that they favour older studies. Among the top 100 list, only two articles from 2012 were included and the articles published after 2012 did not have enough citations to be included in top 100 list. Therefore, we conducted a subgroup analysis of top 100 articles published after 2011. A bibliographic analysis of top cited articles published in the last five years (2012-2017) showed different results from our original search. Only two studies from the sub group analysis were included in the primary analysis due to a lower number of total citations received. Studies 2012, and onwards were focused on latest developments in the field of MM including therapeutic agents such as novel proteasome inhibitors (carfilzomib, ixazomib), monoclonal antibodies (daratumumab, elotuzumab), and chimeric antigen receptor T cell therapy [7-11].

Our primary limitation was conducting the search in the "title mode". Therefore, articles that did not contain MM in the title were not retrieved or included in our study. Secondly, our search was limited to the WOS database which excludes citations of textbooks and other databases which are weaker at tracking older publications. Finally, articles published in languages other than English were excluded.

\section{Conclusions}

This bibliographic analysis provides a list of the 100 top-cited articles in MM along with the captivating comprehension of the history and development in various aspects of disease processes. The landscape of MM is rapidly evolving, and bibliometric studies such as the one we present provides a valuable tool that can highlight important transitions in the field. As new evidence continues to emerge, these types of analyses can provide a quantitative instrument to guide the researchers and funding agencies to assess the overall direction of the field with limited health care resources.

\section{Additional Information Disclosures}

Conflicts of interest: In compliance with the ICMJE uniform disclosure form, all authors declare the following: Payment/services info: All authors have declared that no financial support was received from any organization for the submitted work. Financial relationships: All authors have declared that they have no financial relationships at present or within the previous three years with any organizations that might have an interest in the submitted work. Other relationships: All authors have declared that there are no other relationships or activities that could appear to have influenced the submitted work.

\section{Acknowledgements}

We thank Ms. Marsha A Halajian for editing and final proofing of the manuscript.

\section{References}

1. Michels TC, Petersen KE: Multiple myeloma: diagnosis and treatment. American family physician. 2017, 95:373-383.

2. Fitzmaurice C, Allen C, Barber RM,et al.: Global, regional, and national cancer incidence, mortality, years of life lost, years lived with disability, and disability-adjusted life-years for 32 cancer groups, 1990 to 2015: a systematic analysis for the global burden of disease study. JAMA Oncol. 2017, 3:524-548. 10.1001/jamaoncol.2016.5688

3. Pilkington A: Bibliometrics at Royal Holloway. Enterprise Engineering. 2009, 


\section{Cureus}

4. Miao Y, Liu R, Pu Y, Yin L: Trends in esophageal and esophagogastric junction cancer research from 2007 to 2016: a bibliometric analysis. Medicine. 2017, 96:e6924.

5. Powell AG, Hughes DL, Wheat JR, Lewis WG: The 100 most influential manuscripts in gastric cancer: a bibliometric analysis. Int J Surg. 2016, 28:83-90. 10.1016/j.ijsu.2016.02.028

6. Sackett DL, Rosenberg WM, Gray JA, Haynes RB, Richardson WS: Evidence based medicine: what it is and what it isn't. BMJ. 1996, 312:71.

7. Stewart AK, Rajkumar SV, Dimopoulos MA, et al.: Carfilzomib, lenalidomide, and dexamethasone for relapsed multiple myeloma. N Engl J Med. 2015, 372:142-152. 10.1056/NEJMoa1411321

8. Lokhorst HM, Plesner T, Laubach JP, et al.: Targeting CD38 with daratumumab monotherapy in multiple myeloma. N Engl J Med. 2015, 373:1207-1219. 10.1056/NEJMoa1506348

9. Lonial S, Vij R, Harousseau JL, Facon T, et al.: Elotuzumab in combination with lenalidomide and low-dose dexamethasone in relapsed or refractory multiple myeloma. J Clin Oncol. 2012, 30:1953-1959. 10.1200/jco.2011.37.2649

10. Zonder JA, Mohrbacher AF, Singhal S, et al.: A phase 1, multicenter, open-label, dose escalation study of elotuzumab in patients with advanced multiple myeloma. Blood. 2012, 120:552-559. 10.1182/blood-2011-06-360552

11. Garfall AL, Maus MV, Hwang WT, et al.: Chimeric antigen receptor T cells against CD19 for multiple myeloma. N Engl J Med. 2015, 373:1040-1047. 10.1056/NEJMoa1504542 